\title{
Pesquisa Aplicada em Linguagem: Alguns Desafios para o Novo Milênio
}

(Applied Research in Language: Challenges for the New Millenium)

\author{
Carlos Alberto FARACO \\ (Centro Federal de Educação Tecnológica do Paraná)
}

ABSTRACT: The text presents a critical reading of hegemonic ways of conceiving verbal language in Linguistics as a starting point for a reflection on some challenges to the future of applied researches in language.

KEY-WORDs: Intersubjectivity; Discourse; Dialogism; Applied Research.

Resumo: Faz-se uma leitura critica de modos hegemônicos de conceber a linguagem verbal em lingüistica como ponto de partida para uma reflexão sobre alguns desafios para ofuturo das pesquisas aplicadas em linguagem.

Palavras-CHaVe: Intersubjetividade; Discurso; Dialogismo; Pesquisa Aplicada.

Não parece absurdo afirmar que desde os gregos, dois grandes modos organizam os estudos da linguagem: um modo retórico e um modo lógicogramatical. O primeiro - que antecedeu em alguns séculos o segundo se constituiu a partir do enfrentamento da linguagem verbal como realidade vivida. O outro é produto das abstraçôes que permitiram enfocar a língua como um sistema formal, como uma realidade em si.

Também não parece absurdo afirmar que o milênio que terminou foi o da hegemonia do modo lógico-gramatical. Se isso é já evidente nos primeiros séculos do II milênio com a gramática dos modistas e sua direção universalizante; é particularmente visível nos dois últimos séculos que encerram o milênio, período em que, no contexto da forma moderna de se fazer ciência, se constituiu a lingüística.

Durante os primeiros cem anos desse novo empreendimento intelectual, os estudiosos dedicaram-se à pesquisa fundamentalmente histórica, 
ora comparando línguas e reconstruindo seus estágios anteriores, ora buscando definir a própria dinâmica da mudança lingüística.

Nesse primeiro período, manipularam-se incontáveis dados lingüísticos, em especial em suas dimensões morfológica e fonético-fonológica. Esse vasto exercício empírico centrado em propriedades gramaticais das línguas contribuiu fortemente para o redesenho do objeto língua como um objeto autônomo e da lingüística como a ciência que estuda a língua em si. Sobre aquele objeto autônomo vai-se debruçar também o segundo século dos estudos lingüísticos, agora a partir de um viés fundamentalmente sincrônico.

A autonomia do objeto, se, de um lado, criou condiçôes para o estabelecimento de uma tradição epistemologicamente muito produtiva; de outro, reiterou a eliminação dos falantes e do vivido de seu espaço teórico, ruptura até hoje sem solução teórica adequada, a sugerir - ousamos dizer a partir de sua extensão mais que milenar (já que o corte está entre nós desde os gregos), que se trata, de fato, de uma aporia: o que temos parecem ser dois blocos analíticos distintos e aparentemente irreconciliáveis elaborados em resposta à mesma grande questão em torno da realidade da linguagem.

Hegemônico, o modo lógico-gramatical expulsou do palco os atores e construiu uma língua sem falantes, gesto que, como dissemos acima, tem sido heuristicamente poderoso, motivando a elaboração de sucessivos quadros analíticos de inegável beleza arquitetônica que buscam modelizar a língua assim construída.

Quando, porém, por casual necessidade, é preciso fazer alguma menção aos falantes no interior desses quadros analíticos, o que emerge é uma figura sobre cujo perfil vale a pena se debruçar um pouco, porque ela não só faz aflorar um elemento que está presente na teia obscura daquele nãodito que sustenta as asserçóes teóricas; que participa do processo epistemológico sem se fazer facilmente visível (sem ser, portanto, um problema); mas também revela grandes compromissos de fundo das teorias, o que permite apreender uma complexa e interessante constelação discursiva, a qual, normalmente, nos escapa da vista.

No caso do falante, o que em geral aflora nos textos dos lingüistas formais é a concepção tradicional de pessoa humana - transformada, já há 
algum tempo, em elemento de senso comum, mas que contamina poderosamente as elaboraçōes teóricas. $\mathrm{O}$ falante não passa aí de uma superfície lingüística plana (univocal); é entendido como um ente autônomo (vive num vácuo social e histórico: suas relações sociais são acessórias, quando não de todo irrelevantes); como a origem absoluta da fala (o olhar dos lingüistas formais é fortemente unidirecional e monológico: o falante tem total precedência sobre o ouvinte e sobre a interlocução); e como uniforme interiormente (o máximo que se diz sobre o mundo interior do falante é que ele tem um saber gramatical específico que lhe viabiliza a fala).

Podemos observar facilmente, por essas características, que a imagem que permanece soberana, quando é necessário mencionar o falante na lingüística formal, é aquela do indivíduo construída pelo pensamento pósmedieval, no período que vai dos séculos XV/XVI até o Romantismo.

Será no Romantismo, entendido aqui não apenas como um movimento estético, mas como uma grande cosmovisão, que se produzirá a síntese desse caminho de três séculos. E é justamente no contexto do Romantismo que vão se formar as grandes discussões modernas sobre a linguagem, seja na abordagem analítica dos lingüistas histórico-comparatistas, seja nas reflexōes de caráter mais filosófico de W. Humboldt.

O processo de problematização radical do conceito tradicional de pessoa humana- que se desenvolveu no correr dos séculos XIX e XX - nunca chegou a ter efetiva repercussão no interior da lingüística formal (ver Faraco e Negri (1998) para alguns detalhes desse processo). E isso, obviamente, não é surpreendente. Ao centrar seu foco de atenção na língua em si, a lingüística não pode ter, ao mesmo tempo, o falante como um problema, $\mathrm{o}$ que a deixa permanentemente comprometida com uma determinada imagem cristalizada da pessoa humana.

Mesmo quando, na dialetologia e na sociolingüística, o falante parece surgir como elemento relevante para o estudo de fenômenos lingüísticos, não se vai, de fato, muito além de um ser genérico e quase abstrato, em quem interessa tão somente identificar algumas poucas características de sua situação no mundo e observar repercussōes dessas características sobre sua pronúncia, sua sintaxe e seu léxico. Esses estudos dão, de fato, atenção aos elementos lingüísticos em variação e não propriamente ao falante. Esse continua aí a ser um ente não problemático a respeito de quem pouco se precisa dizer. 
Igualmente não se vai muito além de um ser genérico e quase abstrato, quando se discute a interação face-a-face. Em geral, olha-se, nesses estudos, menos para o falante e mais para a dinâmica da conversação, primeiro assumindo-a como um acontecimento fortuito e, segundo, como um jogo em que interessam os lances em si, mas não os jogadores.

De todo o perfil resumido acima, interessa-nos destacar aqui o viés fortemente unidirecional e monológico que atravessa as análises lingüísticas. Esse viés é inevitável numa visão de mundo articulada a partir do indivíduo. Se ele é o elemento primitivo, princípio teórico de tudo (se ele explica em vez de ser explicado), a fala, por exemplo, terá de ser entendida fundamentalmente como elaboração e emissão. A recepção será apenas seu espelho e a interlocução um insignificante acidente.

Para exemplificar esse nosso argumento, vamos usar um texto muito citado entre nós (Franchi 1977 - aqui referido pela republicação de 1992) e cuja visão de mundo exemplifica bem a força do olhar unidirecional e monológico dos lingüistas, bem como o comprometimento com a imagem tradicional da pessoa humana quando é necessário referir-se ao falante.

Nesse texto, o autor, depois de vários comentários críticos a diferentes concepçōes de linguagem "como transparecem de teorias lingüísticas contemporâneas" (p.10), explicita, com invulgar brilhantismo, sua própria concepção. Não nos interessa aqui fazer dela uma leitura crítica, para o que, certamente, o espaço é insuficiente. Interessa-nos apenas exemplificar nosso argumento.

Ao se ler o texto a partir da página 24, vão ficando claras as alianças tecidas pelo autor com a concepção da pessoa humana sintetizada pelo Romantismo. A linguagem é vista como atividade constitutiva quaseestruturante de um ente de que se diz pouco no texto, mas a respeito de quem se sugere bastante, principalmente quando se retomam as palavras de Humboldt (p.28).

O agente da linguagem é claramente apresentado como um indivíduo singular e solitário. Ele - independentemente da comunicação (e essa independência é reiterada várias vezes no texto) - age interiormente com a linguagem constituindo sua própria experiência. É lapidar, nesse sentido, a assertiva de que "antes de ser para a comunicą̧ão, a linguagem é para a elaboração"(p.25). 
Em todo o texto, a interação é secundarizada; é tornada acidente; é reduzida a tarefas de ocasião. Quando acontece, é entendida como um movimento do agente da elaboração (elemento primitivo do quadro geral) em direção aos outros. Certamente não é gratuita, nesse ponto, a idéia da comunicação como o estabelecimento, com os outros, de laços contratuais (p.25), que nos remete diretamente à filosofia política do século XVIII.

Há, porém, um momento que chama a atenção. Fala-se da linguagem como "um trabalho que dá forma ao conteúdo variável de nossas experiências" (p.31) e se afirma (num aparente paradoxo - se pensarmos no conjunto da discussão) ser esse um trabalho coletivo.

Resolve-se, porém, facilmente o aparente paradoxo, se se observar que coletivo é entendido como um processo de identificação e contraposição do um (o agente elaborador) com os outros, um movimento unidirecional, portanto, pelo qual o coletivo se faz por uma espécie de concessão das partes (coerente, portanto, com a perspectiva dos laços contratuais mencionada acima).

É preciso deixar claro - em especial no contexto de uma reflexão sobre a pesquisa aplicada em linguagem que, em geral, se assume como inter, multi e transdisciplinar - que a concepção da pessoa humana presente no texto que vimos analisando, que toma o indivíduo como o elemento primitivo, não é exclusiva dos lingüistas. Ela está subjacente a inúmeras outras teorizações nas ciências sociais e, certamente, resistirá ainda um bom tempo como base de compreensão de realidades humanas.

De fato, parece que estamos diante de um exemplo daquilo que o Foucault de $A$ arqueologia do saber chama de episteme (p.217), isto é,

O conjunto das relações que podem unir, em uma dada época, as práticas discursivas que dão lugar a figuras epistemológicas, a ciências, eventualmente a sistemas formalizados; o modo segundo o qual, em cada uma dessas formaçôes discursivas, se situam e se realizam as passagens à epistemologização, à cientificidade, à formalização; a repartição desses limiares que podem coincidir, ser subordinados uns aos outros, ou estarem defasados no tempo; as relaçôes laterais que podem existir entre figuras epistemológicas ou ciências, na medida em que se prendem a práticas discursivas vizinhas mas distintas.

Em outras palavras, parece que a concepção de indivíduo (assumido como primitivo) é o elemento articulador de um conjunto de rela- 
ções que torna possível, numa época dada, a existência de diferentes modelações teóricas.

O interesse de nossa reflexão aqui não é, porém, descrever essa poderosa episteme. Seguimos apenas uma sugestão do próprio Foucault (à página 29 de $A$ arqueologia do saber) que nos tem parecido importante: problematizar de alguma forma essa episteme e mantê-la em suspenso; "sacudir a quietude com a qual [a] aceitamos"; mostrar que ela não se justifica por si mesma, que é "sempre o efeito de uma construção cujas regras devem ser conhecidas..."

Como parte desse exercício de sacudir a quietude com que aceitamos o domínio hegemônico da língua como objeto autônomo e do falante como um ente não problemático (e, portanto, assumido como o primitivo - em geral dissimulado - das teorizações), é interessante acompanhar uma outra linhagem intelectual que vem, aos poucos, se contrapondo à primeira. Difusa ainda, essa linhagem de pensamento vem adquirindo contornos desde o início do século XIX, amplia-se no XX e continua em processo de construção, o que não é de espantar, se considerarmos que o pensamento ao qual ela vai-se contrapondo precisou de pelo menos 300 anos para sair de suas primeiras expressões na Renascença e atingir sua plenitude no Romantismo, passando pelo cogito cartesiano no século XVII e pela filosofia política do XVIII.

Essa linhagem vai assumir como fundamento a intersubjetividade, isto é, vai fazendo crescer a idéia de que é impossível pensar o ser humano fora das relaçóes com o outro. Em conseqüência, vai pondo em xeque a precedência do indivíduo e asserçóes de que a linguagem antes de ser para a comunicação é para a elaboração. Na perspectiva da intersubjetividade, a elaboração só se torna possível mediada pela comunicação.

Assim fundada, a atividade intelectual começa a se abrir para a relevância da alteridade, da interação, da subjetividade social; e, por conseqüência, para um progressivo senso de que a apreensão e a compreensão das realidades humanas passam sempre e necessariamente por processos interrelacionais. A interação, nesse quadro, não pode ser , de modo algum, secundarizada. Também não pode ser reduzida a soluções contratuais ou a uma espécie de contradança entre pares que se encontram fortuitamente. A interação, longe de ser apenas acidente (tarefa de ocasião), adquire um caráter de organicidade. É ela que passa a explicar. 
Essa percepção, expressa de início (e até paradoxalmente) pelos filósofos idealistas alemães no início do século XIX, voltará em Marx com a ênfase nas relaçóes sociais no interior do quadro dos modos de produção; e também nos grandes romances de Dostoiévski, com o senso estético da realidade multivocal e dialógica do existir humano; do que, por sua vez, encontraremos ecos nas críticas de Nietzsche às filosofias essencialistas.

No século XX, estará em formulações religiosas e éticas como em Martin Buber ou Emanuel Lévinas; na teoria da cognição de Vygotski; na psicanálise de Lacan; e em várias correntes filosóficas, bastando lembrar do existencialismo, ou de Habermas, ou de Ricoeur; sem esquecer de Bakhtin que foi quem explorou extensamente a questão da intersubjetividade justamente no âmbito da linguagem que, por razões óbvias, está no centro de toda essa concepção, mas que, por força da poderosa episteme que sustenta a lingüística, é ainda motivo de inúmeros embaraços e dilemas.

A questão da intersubjetividade começa a tomar corpo, como dissemos acima, no início do século XIX, nos textos dos filósofos idealistas alemães. Trata-se de um momento particularmente interessante da história moderna em que os efeitos da revolução industrial começam a se fazer visíveis e o trabalho (o agir humano) vai-se tornando tema de reflexão filosófica sistemática.

No começo dessa problematização do agir humano, aparecem as primeiras elaborações que - mesmo descontadas todas as coordenadas idealistas (o indivíduo é ainda o ponto de partida) - vão pondo em questão o solipsismo transcendental de Descartes (em que o eu aparece como unidade imediatamente presente a si mesmo na intuição do cogito) e chegam à dialética hegeliana do reconhecimento (em que o eu só aparece como presença de si para si mesmo pela mediação do outro).

No meio, está, por exemplo, Fichte que, no seu Doutrina da Ciência, avança a discussão de que o autoconhecimento não se realiza fora da atividade (o eu não pode pôr-se a si mesmo como presente sem exercer uma atividade; ao conhecer o não-eu pela atividade, o eu se abre, então (e só então) ao próprio conhecimento. Em outras palavras, entre o eu e ele próprio está o não-eu; só posso, portanto, conhecer-me de forma mediada, isto é, se entre mim e mim mesmo estiver o não-eu, um outro. 
Com a entrada de um negativo (de um não-eu no eu), rompe-se a unidade indiferenciada do cogito cartesiano. O não-eu entra como infinidade, porque sendo qualitativamente outro é também infinitamente outro. O não-eu é infinitamente outro, diferença absoluta, mas ao mesmo tempo identidade, porque o acolho em mim e o coloco como mediação na distância que vai de mim a mim.

Tudo isso será ainda muito trabalhado até chegarmos, cento e poucos anos depois, a Bakhtin com sua teoria dialógica do discurso. Mas por aí fica já bem claro que nos fundamentos remotos do dialogismo (como tem sido hábito chamar o pensamento de Bakhtin) está a percepção de que o si não é sem o outro.

Esse quadro de referência estava no horizonte de Bakhtin, como podem testemunhar dois fragmentos particularmente interessantes de suas notas de caderno. No primeiro, diz ele: "Minha própria refração no outro empírico pelo qual tenho de passar para desembocar no eu-para-mim (poderá ser solitário esse eu-para-mim?)" - (p.377). Parece claro que o pano de fundo dessa asserção é a perspectiva da consicência de si como elaborada por Hegel em seu livro Fenomenologia do espirito, onde se lê: "A consciência-de-si é em si e para si quando eporque é em si e para si para uma Outra; quer dizer, só écomo algo reconhecido"- (p.126).

No segundo, diz Bakhtin: "Assim como o corpo se forma originalmente dentro do corpo materno, a consciência do ser humano desperta envolta na consciência do outro. "- (p.378)

Esse quadro conceitual que toma a intersubjetividade como fator constituinte e não constituído - cheio ainda de imprecisões, lacunas e contradições - está irremediavelmente posto no horizonte dos estudos da linguagem. Ele ocupa ainda a margem; não conseguiu ainda estruturar-se em modelos heurísticos sofisticados. Contudo, define um outro modo de olhar a linguagem, essa realidade extremamente complexa e multiface. Um olhar que nos obriga a centrar a atenção sobre as práticas discursivas, ou seja, sobre a língua em sua integridade concreta e viva (e, por conseqüência, concreta e viva na boca de seus falantes) e não na língua como um objeto obtido por meio da abstração radical da vida concreta do discurso, processo este que fundamenta o olhar tradicional da lingüística.

Por mais legítima e produtiva cientificamente que seja essa abstração, temos de reconhecer que ela tem pouco a dizer quando queremos entender 
nossas práticas discursivas, ou seja, a língua como realidade vivida. E, nesse sentido, essa poderosa abstração tem pouco a dizer quando se trata de pensar as inúmeras situações de pesquisas aplicadas em linguagem que envolvem sempre e necessariamente a língua como realidade vivida, da qual não se pode, obviamente, excluir os falantes.

Assim, parece ser indispensável deixar que a crítica radical à imagem tradicional da pessoa humana ressoe, enfim, nos estudos lingüísticos; é fundamental que a intersubjetividade deixe de ser abordada como acidental ou fortuita e passe a ser abordada como eixo orgânico da realidade lingüística.

Ao mesmo tempo, nas pesquisas aplicadas em linguagem, será necessário fazer a crítica radical aos pressupostos que ainda são devedores de uma concepção abstrata da linguagem e de uma perspectiva em que o indivíduo é ainda, mesmo que dissimuladamente, o primitivo de nossas elaborações teóricas. Um projeto e tanto para o novo Milênio!

\section{REFERÊNCIAS Bibliográficas}

BakHtin, M.M. (1979) Estética da Criação Verbal. São Paulo: Martins Fontes, 1992.

Faraco, C.A. \& L. Negri (1998) O falante: que bicho é esse, afinal? Letras, 49. Curitiba: Editora da UFPR: 159-170.

Fichte, J.G. (1804) Doutrina da Ciência. In: Fichte. São Paulo: Abril Cultural, 1975. (Coleção Os Pensadores).

Foucault, M. (1969) A Arqueologia do Saber. 5ªed. Rio de Janeiro: Forense Universitária, 1997.

FranCHI, C. (1977) Linguagem - atividade constitutiva. Cadernos de Estudos Lingüísticos, 22: 9-39, Jan./Jun. 1992. Campinas: IEL/Unicamp. Hegel, G.W.F. (1807) Fenomenologia do Espirito - I. 4aed. Petrópolis: Vozes, 1999. (Coleção Pensamento Humano). 